\title{
Radiological evaluation of deep soft tissue fibromatosis, the characteristic MR criteria on conventional and corresponding diffusion-weighted images
}

\author{
Rania Zeitoun ${ }^{1 *}$ (D), Sarah Maged Khafagy², Ikram Hamed Mahmoud² and Nagui Mohamed Abd El-Wahab
}

\begin{abstract}
Background: To analyze the characteristic features of deep fibromatosis on conventional and diffusion-weighted MR images.

Result: The lesions were growing along the musculoaponeurotic fascia, mostly invaded the muscles, and showed ill-defined margins, low T2 signal bands and areas, and facial tail sign. Diffusion images showed mostly high or high mixed with low signal; only 2 lesions showed a persistent low signal. The average mean and minimum ADC values were $1.41 \pm 0.26 \times 10^{-3} \mathrm{~mm}^{2} / \mathrm{s}$ and $0.79 \pm 0.43 \times 10^{-3} \mathrm{~mm}^{2} / \mathrm{s}$ respectively. Post-contrast and DWI detected synchronous lesions and extensions missed on $\mathrm{T} 1$ and $\mathrm{T} 2$ images.

Conclusion: The most frequent MR features of deep fibromatosis are low T2 signal bands and areas, fascial tail sign, ill or partially defined margins, and predominant restricted diffusion pattern in addition to areas of "T2-blackout effect." Post-contrast and DWI are more valuable in local staging of the tumor.
\end{abstract}

Keywords: Fibromatosis, Desmoid, Soft tissue tumors, MRI, DWI

\section{Background}

Musculoskeletal fibromatosis represents soft tissue tumors with neoplastic fibroblastic and myofibroblastic cells proliferation. Deep fibromatosis represents the subtype of these soft tissue neoplasms arising at the intermuscular facial planes. Deep fibromatosis encompasses desmoid extra-abdominal and abdominal wall fibromatoses. Other synonyms of the extra-abdominal type include aggressive fibromatoses and musculoaponeurotic fibromatoses $[1,2]$

Desmoid-type fibromatoses (DF) are defined according to the 2013 version of the WHO classification as "clonal fibroblastic proliferations that arise in the deep soft tissues and are characterized by infiltrative growth and a tendency toward local recurrence but an inability to metastasize."

\footnotetext{
* Correspondence: rania.zeitoun@kasralainy.edu.eg; raniazeitoun@gmail.com 'Department of Diagnostic and Interventional Radiology, Kasr Al-Ainy Faculty of Medicine, Cairo University, 11 rd. 100, Maadi, Cairo, Egypt Full list of author information is available at the end of the article
}

According to their biologic behavior, they are classified as intermediate (locally aggressive) malignancy [3]

The main role of imaging is not to define a lesion to be deep fibromatosis, as this can only be confirmed by histopathological analysis of a biopsied lesion. The role of imaging is mainly to describe the anatomical location, the local extent of the lesion, and its relationship to adjacent structures, especially vital ones as vessels and nerves. Such information is essential for treatment planning. The preferred imaging modality is magnetic resonance imaging (MRI). Monitoring the progress of lesion growth is another value for imaging, especially in cases addressed to an initial watchful waiting policy $[1,4]$

Diffusion-weighted (DW) MR images and their quantitative counterpart, apparent diffusion coefficient (ADC value), provide helpful information about the cellularity of tumors while the scanning time is short and no need for intravenous contrast administration [5-7] Different research studies were conducted to evaluate diffusionweighted imaging (DWI) role in distinguishing benign 
form malignant soft tissue tumors through implementing quantitative measurement of ADC values. However, most studies presented a limited number of lesions.

In our study, we aimed at analyzing the characteristic features of deep fibromatoses lesions, reflecting their peculiar histopathological composition and heterogeneity, on both conventional MR and DW images, with further attention to qualitative and quantitative DW assessment.

\section{Methods}

\section{Patients}

We performed a retrograde observational lesion-based analysis for musculoskeletal deep fibromatoses lesions. The study was performed at the authors' institute. We reviewed the data bases from December 2015 until January 2017 for all patients. We selected deep fibromatoses patients to record their medical history and pathology results. The study included 32 patients (12 male and 20 female patients) who had 40 pathologically proven deep fibromatoses lesions: 37 extra-abdominal and 3 abdominal wall lesions. The patients' ages ranged from 2 to 75 years. We excluded patients whose pathology results or data were not available or MR imaging protocol is not complete.

\section{MR imaging}

A high-field system (1.5 Tesla) closed magnet unit (Phillips Achieva XR) was used to scan the enrolled patients and the optimal coil covered the examined part for each patient. MR protocols are as follows:

Pre-contrast imaging included T1-weighted images (T1WIs) and T2-weighted images (T2WIs).

Contrast-enhanced study was performed after bolus injection of $0.1 \mathrm{mmol} / \mathrm{kg}$ body weight of gadolinium-DTPA flushed with $20 \mathrm{ml}$ of sterile $0.9 \%$ saline solution at a rate of $2 \mathrm{ml} / \mathrm{s}$ using an automatic injector. Contrast-enhanced MR imaging using T1WIs and THRIVE (T1 high-resolution isotropic volume excitation) techniques was performed.

Diffusion-weighted MR images were acquired in the axial plane using a fat-suppressed single-shot spinecho echo planar imaging (EPI) sequence with tridirectional diffusion gradients and four $b$ values $(0$, 50,400 , and $800 \mathrm{~s} / \mathrm{mm}^{2}$ ) to increase the sensitivity to cellular packing. ADC was automatically generated for each pixel of the diffusion-weighted image in the form of parametric maps on the operating console or on the workstation.

\section{Images analysis and interpretation}

All images were transferred to a workstation using the Digital Imaging and Communications in Medicine (DICOM) format.

\section{Conventional MR images analyses}

On conventional MRI, the morphological features of each lesion were recorded including the following: site and origin, size, margin, signal characteristics on T1 and T2 WIs, pattern and intensity of enhancement on post-contrast images, low T2 signal bands, facial tail sign, extra-compartmental extension, bone invasion, and neurovascular compromise.

Regarding signal stratification on T1 and T2 images, the signal of normal muscles is taken as reference, so a lesion's signal is either intermediate (iso-intense to that of normal muscle), low (hypo-intense to that of normal muscle), or high (hyper-intense to that of normal muscle).

\section{DWI analysis}

\section{Qualitative analysis}

The signal intensity of different lesions was analyzed and recoded for both the DWIs (at the highest $b$ value, i.e., at $800 \mathrm{~s} / \mathrm{mm}^{2}$ ) and the ADC map.

\section{Quantitative analysis}

The mean and minimum ADC values were measured on the ADC map by drawing an elliptical region of interest (ROI), over the largest area of the lesion showing the highest visible signal on the DWIs. ROIs were manually placed within the boundaries of the lesion using an electronic cursor. Areas that may influence the ADCs as necrotic and hemorrhagic areas as well as fibrosis, adjacent normal tissue, fat, and bone were avoided through correlation to the T2 and post-contrast images. We calculated the average values for the obtained mean and minimum ADC values.

\section{Comparative analysis of $\mathrm{T} 1$ and $\mathrm{T} 2$ images vs. post- contrast and DWI images}

Intra- and extra-compartmental extensions and neurovascular compromise in each lesion were analyzed comparatively on T1 and T2 vs. post-contrast and DWIs.

\section{Results}

We studied 40 pathologically proven deep fibromatoses lesions: 37 extra-abdominal fibromatoses and 3 abdominal wall fibromatoses. The studied lesions included multiple synchronous lesions at different limbs in 7 patients.

\section{Conventional MR features}

The analyzed features are listed in Table 1 . Three lesions originated at the anterior abdominal wall; the rest extraabdominal is presented at different regions. Only six lesions were seen growing along the musculoaponeurotic fascia and did not invade the muscles while the others showed frank muscle invasion on MR images. Most of the extra-abdominal lesions had ill-defined or partially defined margins. The signal intensity was variable among the lesions and of predominantly heterogeneous pattern 
Table 1 The features of DF lesions on conventional MR images

\begin{tabular}{ll}
\hline & $\begin{array}{l}\text { Number of lesions } \\
\text { (percentage) }\end{array}$ \\
\hline Site and origin & 3 \\
Anterior abdominal wall & \\
Extra-abdominal & 1 \\
$\quad$ Neck & 1 \\
$\quad$ Chest wall & 9 \\
$\quad$ Shoulder girdle and upper arm & 3 \\
$\quad$ Forearm and wrist & 21 \\
$\quad$ Pelvis and thigh & 2 \\
$\quad$ Popliteal fossa and calf & $6(15 \%)$ \\
Fascia & $34(85 \%)$ \\
Muscle & \\
Margins & $18(45 \%)$ \\
III defined & $14(35 \%)$ \\
Partially defined & $8(20 \%)$ \\
Well defined & \\
Size (ranged from 0.8 to $60 \mathrm{~cm}$ in & \\
maximum diameter, the mean & \\
tumor size 10.7 cm) & \\
Signal (Table 2) & $33(82.5 \%)$ \\
Low signal bands & \\
Bone invasion tail sign & \\
Neurovascular compromise & \\
\hline &
\end{tabular}

reflecting the heterogeneous histopathological nature of deep fibromatoses lesions (Figs. 1 and 2; Table 2). Areas of low signal intensity of variable configuration (bands or conglomerate bulks) and variable proportions were detected across T2 images in 38 lesions (Figs. 1, 2, and 3). Fascial tail sign was best appreciable and easy to trace on the post-contrast images. It was detected in 33 lesions representing most of the extra-abdominal lesions (Fig. 2). Crossing the fascial planes and infiltration into adjacent compartments (extra-compartmental extension) was encountered in 24 extra-abdominal lesions. Bone invasion was detected in 7 extra-abdominal lesions. In 3 lesions, bone destruction involving the clavicle, ribs and vertebrae, and greater trochanter of the femur was noted. Subtle cortical erosions and bone marrow edema were noted in 4 other lesions. Neurovascular compromise in the form of encasement of the adjacent neurovascular bundles was detected in 19 extra-abdominal lesions.

\section{Diffusion-weighted imaging features Qualitative analysis}

Visual analysis of the DWI at the highest $b$ value $(800 \mathrm{~s} /$ $\mathrm{mm}^{2}$ ) and the ADC map revealed different signal patterns
(Table 2). A predominance of high signal intensity on the DWIs (in 37 lesions) was noticed either mixed with low signal areas (Fig. 1) or purely high signal (Fig. 4). Such high signal turned into intermediate or mixed intermediate and low signal pattern on the corresponding ADC map images, representing diffusion restriction pattern. The previously described low T2 signal bands and conglomerate areas were also noted to be of low signal on DWI. Only 2 lesions presented a homogenous low signal on both the DWIs and the ADC map, representing dense fibrosis (Fig. 5). This is supported by the fact that the same lesions exhibited low signal on T1 and T2 WIs and showed no evidence of enhancement in the post-contrast images. One lesion presented a homogenous intermediate signal on both DWIs and the corresponding ADC map.

\section{Quantitative analysis}

The average calculated mean ADC value is $1.41 \pm 0.26 \times$ $10^{-3} \mathrm{~mm}^{2} / \mathrm{s}$ while the average minimum ADC value is $0.79 \pm 0.43 \times 10^{-3} \mathrm{~mm}^{2} / \mathrm{s}$.

\section{Comparative analysis of T1 and T2 images vs. post- contrast and DWI images}

On conventional MR images (T1 and T2 WIs), 2 synchronous extra-abdominal lesions in 2 different patients were missed (Fig. 6). Intra-compartmental extension in the form of invasion of other muscles in the same compartment was missed in 2 extra-abdominal lesions of different patients. Moreover, extra-compartmental extension was also missed in 4 extra-abdominal lesions. Correspondingly, those missed synchronous lesions and intra- and extra-compartmental extensions exhibited moderate to marked notable enhancement on post-contrast series and diffusion restriction rendering them easily detected (Table 3 ).

\section{Discussion}

Deep fibromatoses are soft tissue tumors of peculiar histopathological composition which in turns is reflected on their imaging features. The included patients' ages ranged from 2 to 75 years; 5 patients (12.5\%) who had extra-abdominal fibromatoses were younger than 10 years. Literature stated that common presentation is between puberty and the age of 40 years with less than 5\% of pediatric age affection [8,9] A female predominance is noted in our study; the 3 abdominal wall lesions were exclusively females at child bearing age $[2,10]$

Multi-centric extra-abdominal fibromatosis was encountered in $7(21.8 \%)$ patients, which is a slightly higher incidence compared with the reported literature being $5-15 \%$ $[2,11,12]$ The majority of the lesions were extraabdominal type, mostly proximal in location, at the pelvic girdle and thighs and at the shoulder girdle and upper arm. They predominantly demonstrated ill or partially defined margins, which is also reported in other studies $[13,14]$ In 

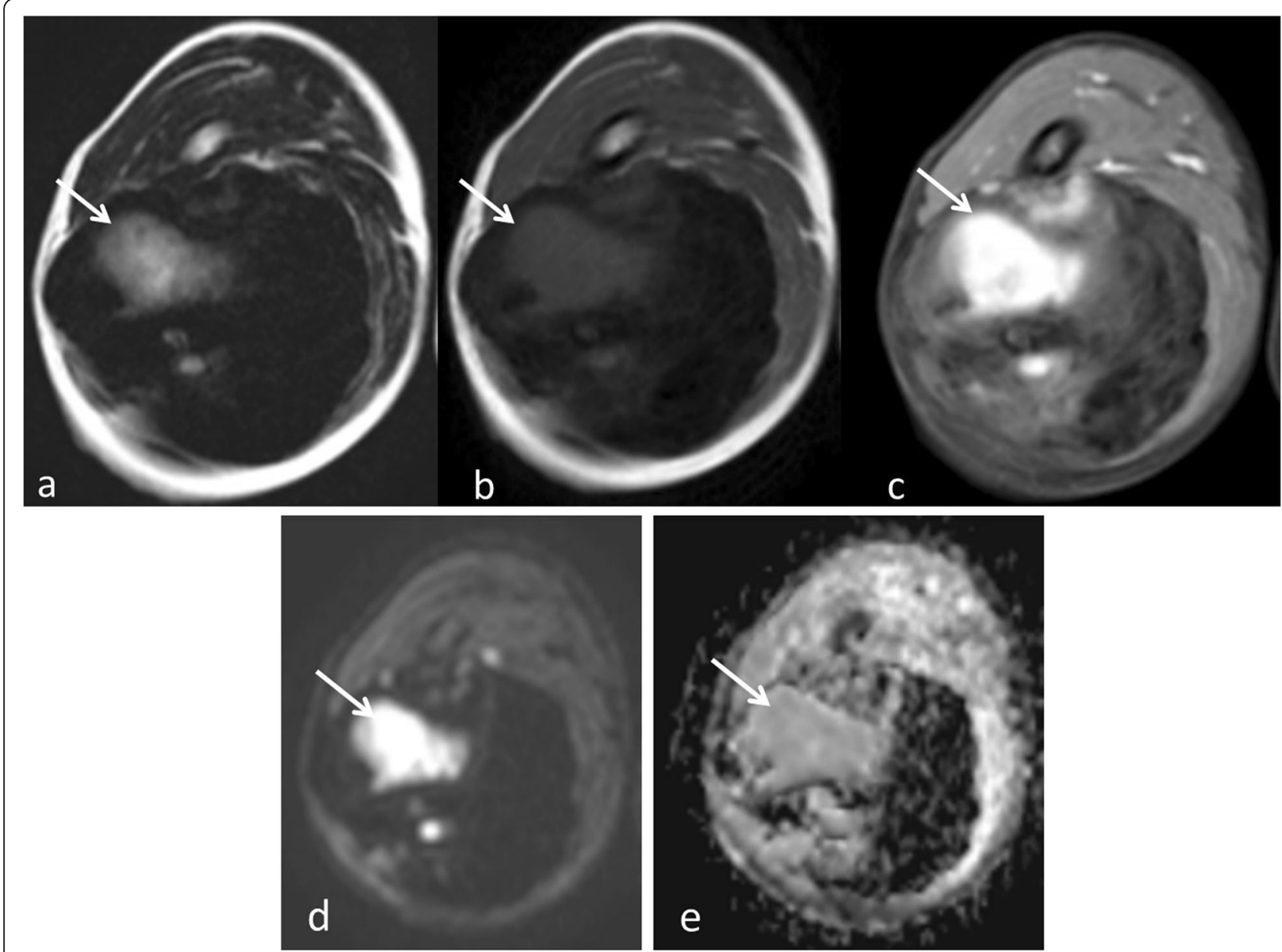

Fig. 1 Right thigh fibromatosis presenting in a 9-year-old male; a axial T2, b axial T1, c axial post-contrast THRIVE, d DWI, and e ADC images showing characteristic signal pattern. The central part of the lesion (arrow in $\mathbf{a}, \mathbf{b}, \mathbf{c}, \mathbf{d}$, and e) showed high T2 signal, low T1 signal, and marked contrast enhancement representing the more cellular part of the lesion and also exhibited high signal on the DWl, intermediate signal on the ADC images denoting restricted diffusion. Note the periphery of the lesion showed persistent low signal area along the T2, DWI, and ADC images and no contrast uptake on the post-contrast THRIVE, representing the predominance of collagen in this area

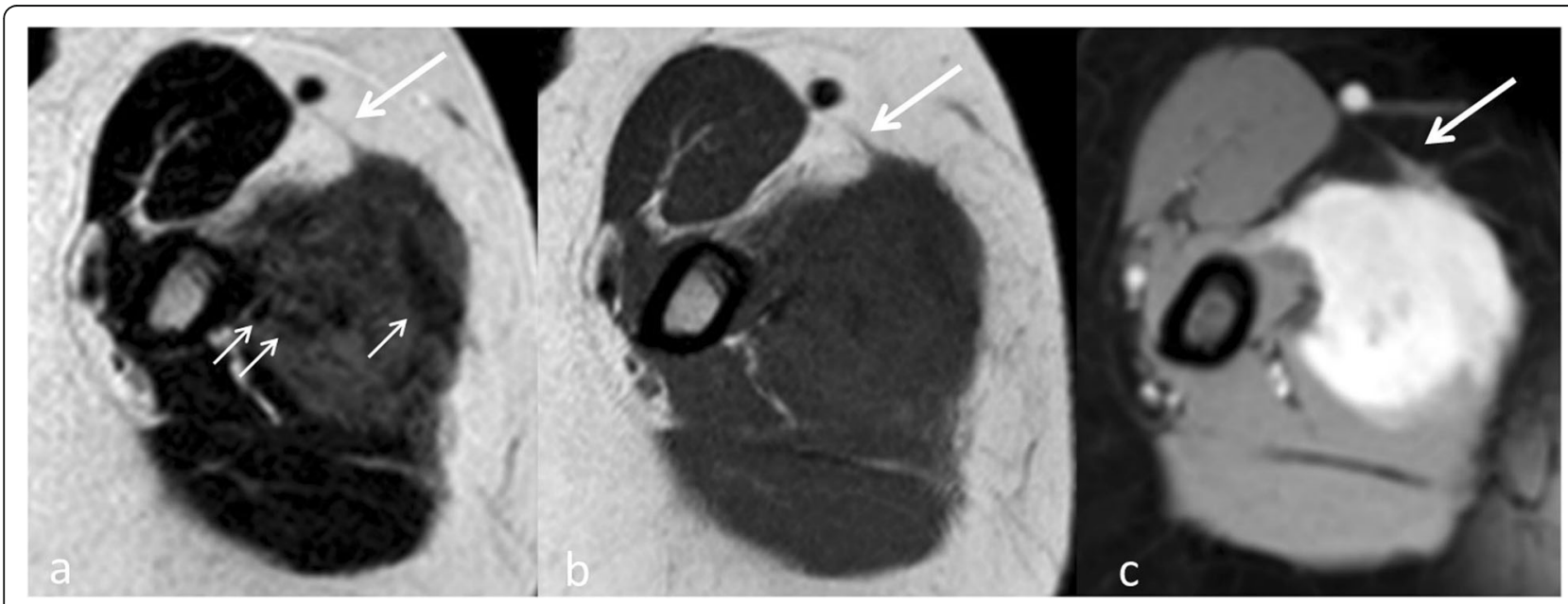

Fig. 2 Left arm fibromatosis presenting in a 39-year- old female; a axial T2, b axial T1, c axial post-contrast THRIVE showed the mass invading both the flexor and extensor compartments of the mid arm with low T2 signal bands (short arrows in $\mathbf{a}$ ) and fascial tail sign (long arrow in $\mathbf{a}, \mathbf{b}$, and $\mathbf{c}$ ) 
Table 2 Signal characteristics of DF lesions on different conventional and diffusion-weighted images

\begin{tabular}{|c|c|c|c|c|c|c|c|c|}
\hline $\begin{array}{l}\text { No. of } \\
\text { lesions }\end{array}$ & T1WI signal & $\begin{array}{l}\text { No. of } \\
\text { lesions }\end{array}$ & T2Wl signal & $\begin{array}{l}\text { No. of } \\
\text { lesions }\end{array}$ & $\begin{array}{l}\text { Contrast } \\
\text { enhancement }\end{array}$ & $\begin{array}{l}\text { No. of } \\
\text { lesions }\end{array}$ & DW signal & ADC signal \\
\hline 2 & Low & 2 & Low & 2 & No enhancement & 2 & Low & Low \\
\hline 15 & $\begin{array}{l}\text { Low to } \\
\text { intermediate }\end{array}$ & 18 & $\begin{array}{l}\text { Low to } \\
\text { intermediate }\end{array}$ & 1 & Mild & 1 & Intermediate & Intermediate \\
\hline \multirow[t]{2}{*}{23} & Intermediate & 17 & Intermediate & 18 & Moderate & 37 & $\begin{array}{l}\text { High or mixed high } \\
\text { and low }\end{array}$ & $\begin{array}{l}\text { Intermediate or } \\
\text { intermediate and low }\end{array}$ \\
\hline & & 3 & $\begin{array}{l}\text { Intermediate } \\
\text { to high }\end{array}$ & 19 & Marked & & & \\
\hline
\end{tabular}

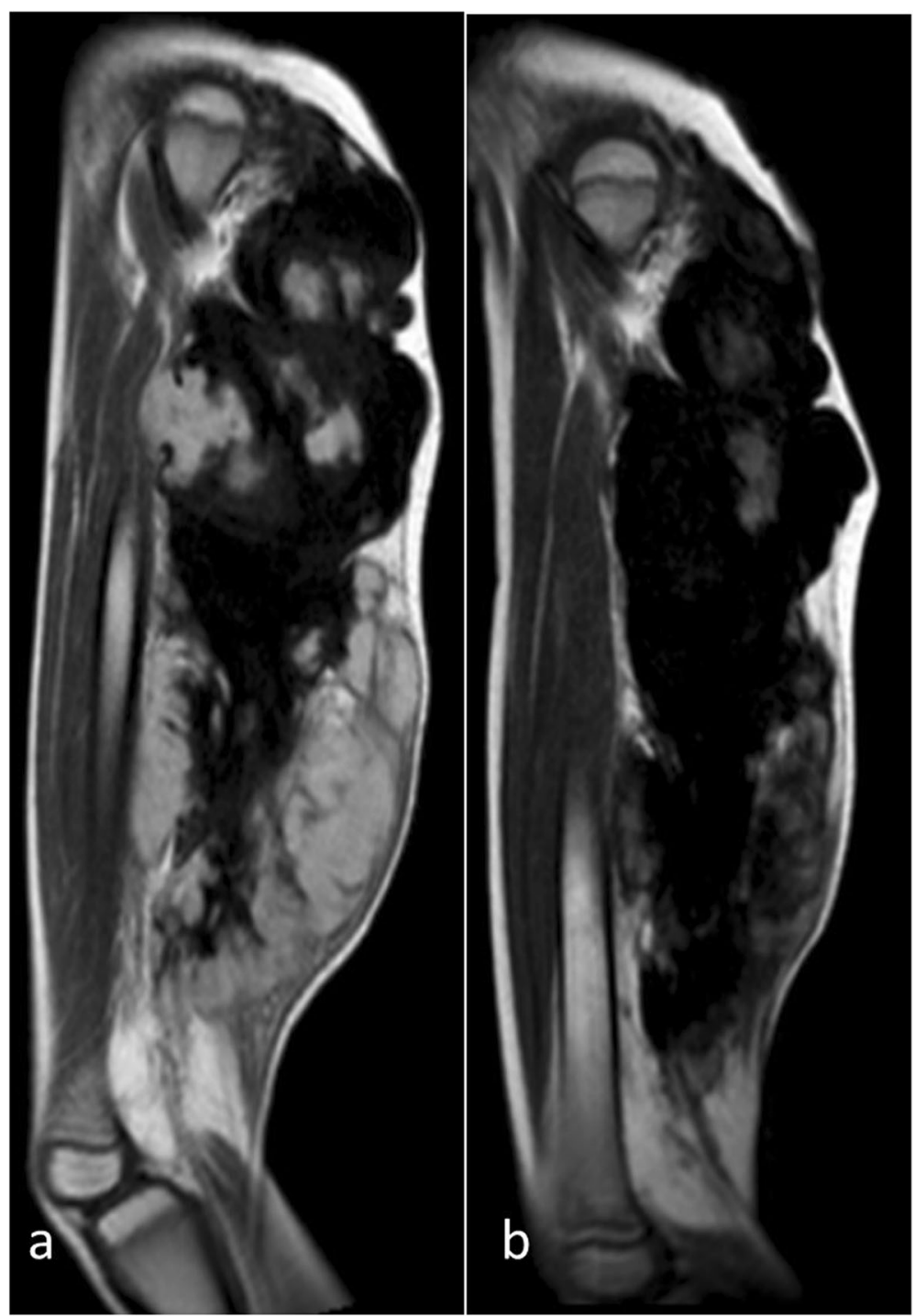

Fig. 3 Right thigh fibromatosis in a 9-year-old male; sagittal T1 post-contrast images a pre-therapy and $\mathbf{b}$ post-therapy showed progressive growth of the low signal fibrous areas within the lesion and reduction of the cellular enhancing areas denoting favorable response to therapy in this case 

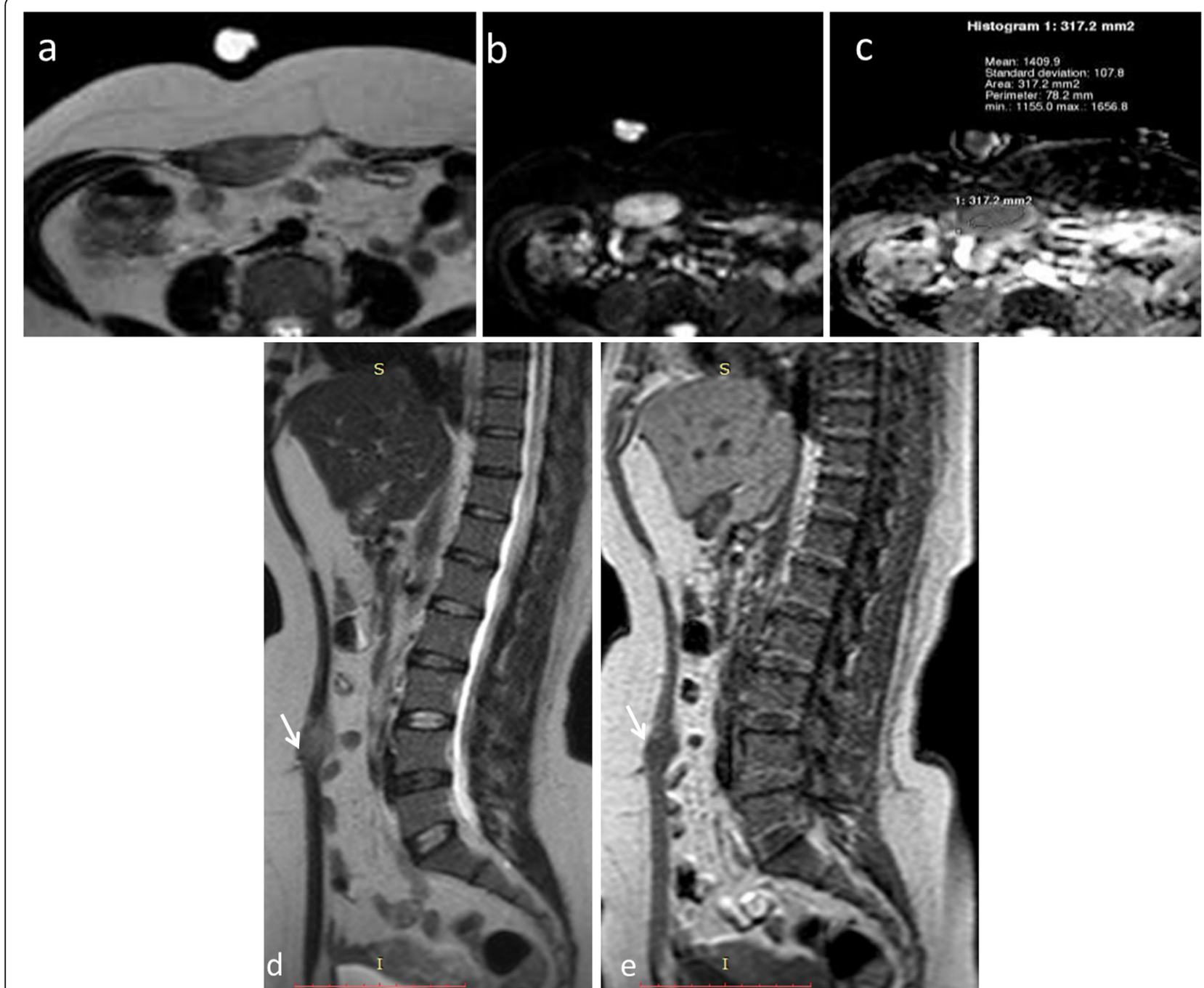

Fig. 4 Anterior abdominal wall fibromatosis presenting in a 41-year-old female a axial T2WI showing a well-defined right rectus abdominis intramuscular lesion of hyper-intense signal relative to the normal muscles; $\mathbf{b}$ axial DWI and $\mathbf{c}$ the corresponding ADC images show that the lesion exhibits high signal on the DWI that turned to intermediate signal on the ADC map. Upon placing a ROI that covered the maximum diameter of the lesion, the mean and minimum ADC values were $1.4 \times 10^{-3}$ and $1.1 \times 10^{-3} \mathrm{~mm}^{2} / \mathrm{s}$ respectively. Sagittal T2 (d) and T1 (e) images; arrow pointing to the same lesion

their study, Quinn et al. concluded that even welldemarcated margins, which was found in half of their studied lesions, are misleading as, microscopically, all of the lesions invaded adjacent structures [14]

On T1-weighted images, the majority of lesions exhibited low and/or intermediate signal intensity, while on T2-weighted images, lesions were mainly of intermediate or mixed intermediate and low signal intensity. Most of the examined lesions showed heterogeneous moderate to marked contrast uptake. This was comparable with signal properties stated in literature $[1,9,13,15]$ Two lesions in our study exhibited predominantly low signal across all of the examined sequences with no evidence of enhancement; this can be attributed to the predominance of collagen and low cellularity.
Areas of persistent low signal intensity across different sequences, pre- and post-contrast images, were seen in 95\% of lesions, varying in shapes (bands, conglomerate bulks) and sizes. Such MR finding has always been described in literature as a valuable diagnostic feature representing acellular collagen $[1,2,15]$ It was not demonstrated in 2 extra-abdominal lesions in our study, reflecting predominance of cellularity and aggressive nature in these lesions. It is worth to mention that these 2 lesions also exhibited restricted diffusion pattern (purely high signal on DWI and intermediate signal on ADC map) as well as moderate and marked enhancement, confirming their aggressive nature along other MR features. Other valuable implementation of such low signal intensity areas is monitoring therapeutic response. A 


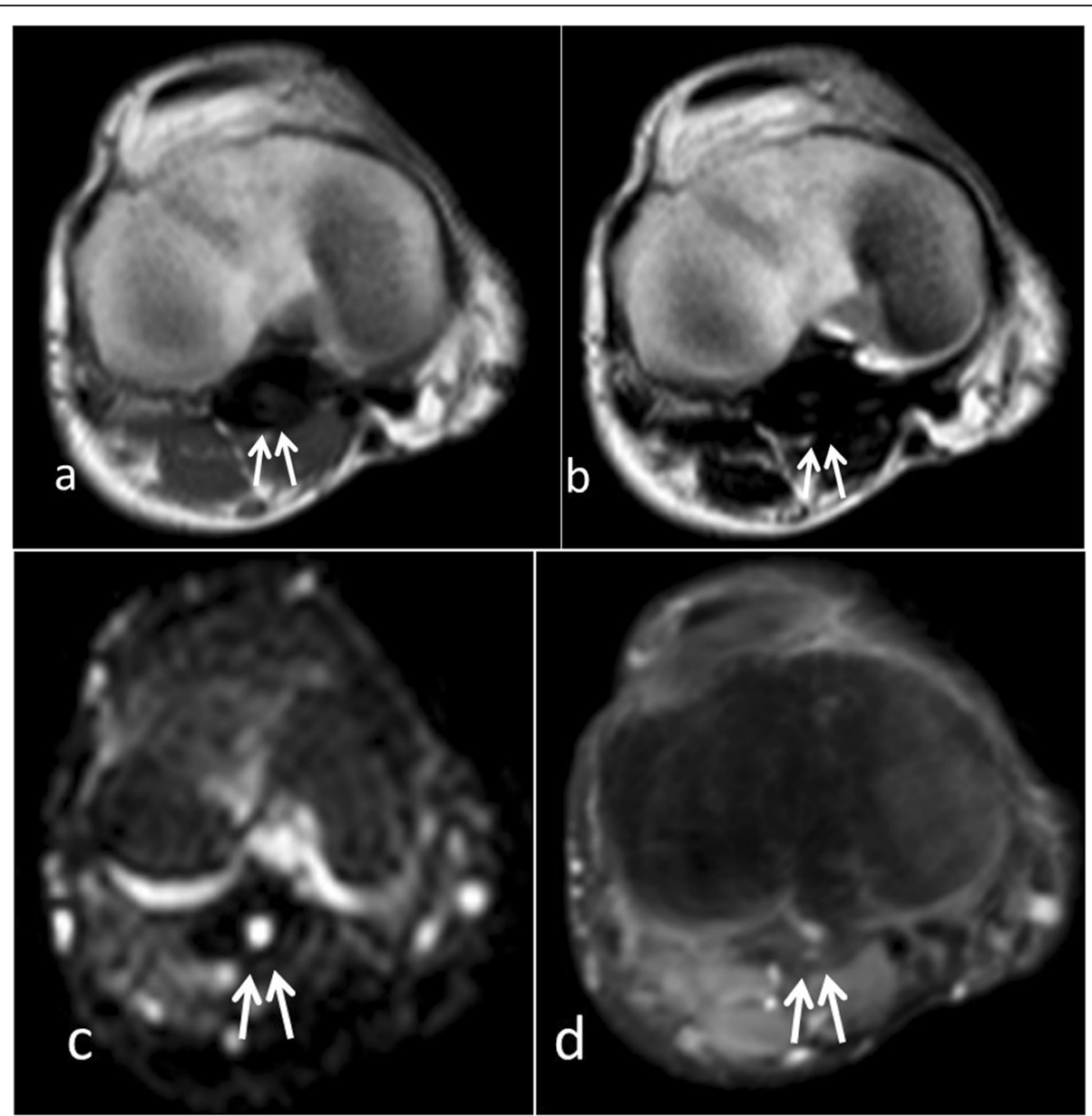

Fig. 5 Popliteal fibromatosis presenting in a 40-year-old male; a axial T1, b axial T2, c axial DWI, $\mathbf{d}$ axial post-contrast THRIVE images: the lesion (arrows) showing hypo-intense signal intensity on T1, T2 images, and DWI and virtually no contrast uptake on post-contrast image

positive response is reached by progressive tumor collagenization; a feature reflected by decreased T2 signal and enhancement among the lesion regardless of it size changes $[1,2]$

Fascial tail sign was demonstrated in $82.5 \%$ of the studied lesions, exclusively extra-abdominal lesions. This is a comparable percentage with that stated in literature $[1,10]$ It was best traced in the post-contrast images. The literature highlighted its importance, not just as distinguishing feature of deep fibromatosis but more importantly as a guide for excision with free surgical margins $[16,17]$

Qualitative analysis of the DWIs and the ADC map showed the predominance ( $92.5 \%$ of lesions) of high signal intensity on the DWIs, whether purely or mixed with low signal areas. On the corresponding ADC map, this was reflected as intermediate or mixed intermediate and low signal intensity, reflecting diffusion restriction. The areas of persistently low signal intensity on both the DWIs and the ADC map corresponded to the previously described low signal bands and areas. Literature described such pattern as indicative of fibromuscular tissue and mature fibrous tissue [18] Other studies described low signal on DWI and ADC as "T2-blackout effect" attributed by factors which produce T2 shortening [19] These low signal areas showed very low mean and minimum ADC values. This can be explained by the fact that fibrous tissue works as an obstacle to water molecules diffusibility. While placing the ROIs, we considered encompassing the largest tumor area possible without including these low signal areas.

In our study, the lesions showed average mean and minimum ADC values of $1.41 \pm 0.26 \times 10^{-3} \mathrm{~mm}^{2} / \mathrm{s}$ and $0.79 \pm 0.43 \times 10^{-3} \mathrm{~mm}^{2} / \mathrm{s}$ respectively. The measured mean ADC values for deep fibromatosis lesions in other studies ranged from 1.2 to $1.9 \times 10^{-3} \mathrm{~mm}^{2} / \mathrm{s}[5,20,21]$ The average mean ADC value in our study is closer to that measured by Oka et al. and Pekcevik Y et al. The average minimum ADC value is far less than minimum $\mathrm{ADC}$ value mentioned by Oka et al.; in their series, however, the authors mentioned as a part of their study limitations that they did not examine the agreement of minimum ADC 


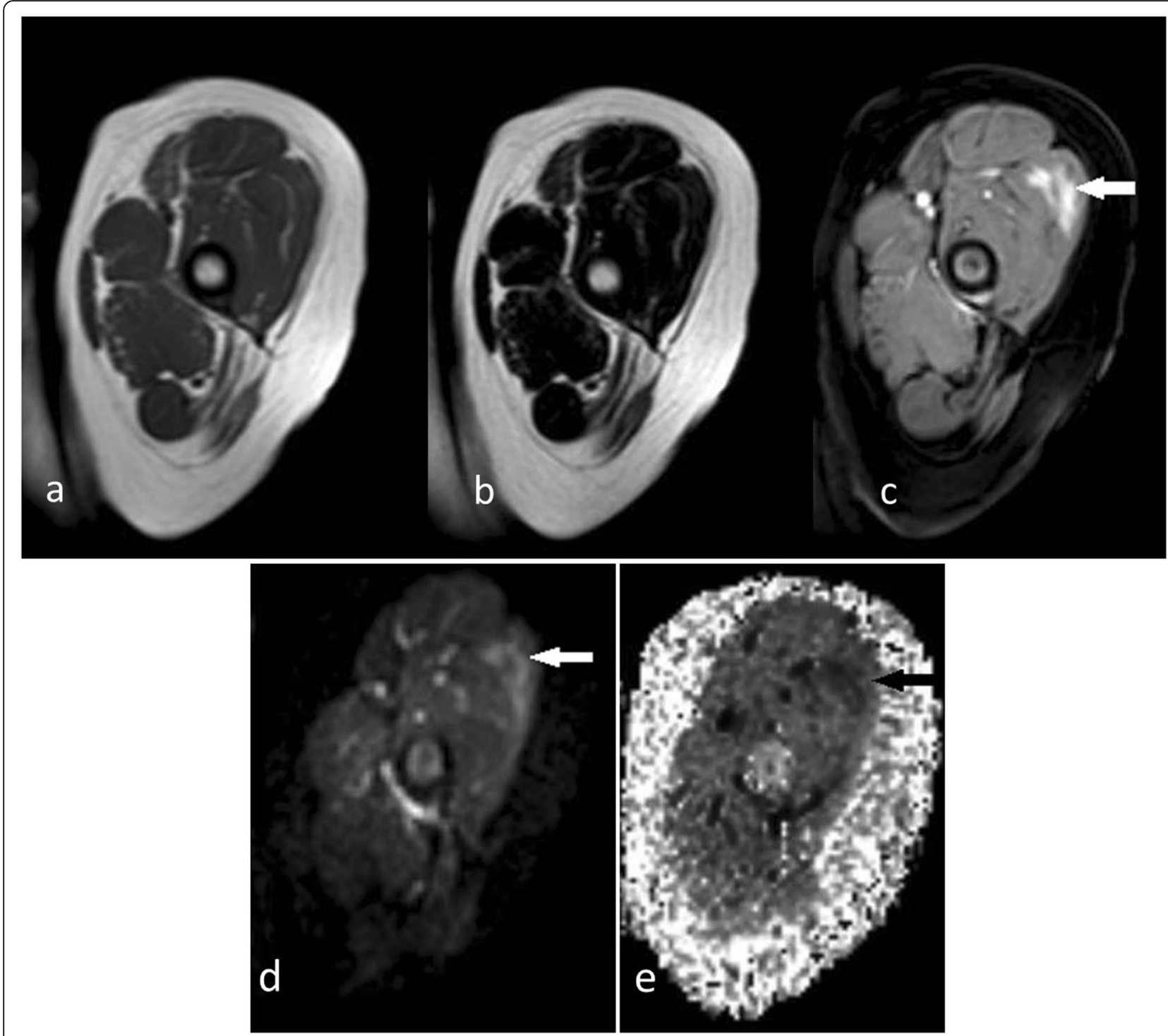

Fig. 6 Left thigh fibromatosis in a 20-year-old male presented as a synchronous lesion in the same patient who had DF lesion at the contralateral limb; a axial T1, b axial T2 images missed a synchronous lesion in this patient. Axial (c) post-contrast images revealed enhancing synchronous lesion (arrow) at the anterior compartment of the left thigh. Axial DWI (d) and ADC (e) revealed diffusion restriction in the same lesion (arrow)

with corresponding lesions' cellularity beside that they included only 8 fibromatoses lesions.

We comparatively reviewed the pre-contrast $\mathrm{T} 1$ and $\mathrm{T} 2$ WIs with the post-contrast images. The post-contrast images are of superior value in accurately assessing the local disease extent. Post-contrast images identified 2 synchronous lesions and accurately delineated extra-compartmental extension in other 4 lesions. Synchronous lesions, intra-compartmental, and extra-compartmental extensions were missed due to intermediate signal on $\mathrm{T} 1$ and $\mathrm{T} 2 \mathrm{WIs}$, rendering them indistinguishable from adjacent or invaded muscles. All missed lesions were readily detected on post-contrast images by virtue of their eminent enhancement, thereby influencing the management plan. They also showed a corresponding diffusion

Table 3 Comparative analysis of T1 and T2 images vs. post-contrast and diffusion images

\begin{tabular}{lllll}
\hline Number of missed lesions & Conventional T1 images & Conventional T2 images & Post-contrast images & DWI \\
\hline Synchronous lesions & 2 & 2 & 0 & 0 \\
Intra-compartmental extension & 2 & 2 & 0 & 0 \\
Extra-compartmental extension & 4 & 4 & 0 & 0 \\
\hline
\end{tabular}


restriction pattern, denoting aggressive nature. The latter has a potential implication in patients suffering renal impairment. In these patients, adding a diffusion sequence to MR study will provide necessary information for management plan meanwhile avoiding harmful effects of contrast administration.

There were some limitations in our study. First, we could not correlate the radiologic findings to microscopic histopathologic appearance as all the included lesions were pathologically proven using needle biopsy. The lack of standardized protocols for placement of ROI to measure ADC value is also a limitation here; however, we unified the methods used in all the included lesions.

\section{Conclusion}

The most frequent conventional MR features in deep fibromatoses lesions are low T2 signal bands and areas, fascial tail sign, ill, or partially defined margins, in addition to their characteristic sites of origin. DWI analysis revealed predominant diffusion-restricted pattern in addition to areas of "T2-blackout effect." Post-contrast and DWI detect synchronous lesions and better evaluate intra- and extra-compartmental extensions; features can be missed on $\mathrm{T} 1$ and $\mathrm{T} 2$ images.

\section{Abbreviations \\ ADC: Apparent diffusion coefficient; DF: Desmoid-type fibromatoses; DICOM: Digital Imaging and Communications in Medicine; DW: Diffusion weighted; DWI: Diffusion-weighted imaging; EPI: Echo planar imaging; MR: Magnetic resonance; THRIVE: T1 high-resolution isotropic volume excitation}

\section{Acknowledgements}

Not applicable.

\section{Authors' contributions}

All authors have made substantial contributions to all four categories established by the International Committee of Medical Journal Editors. All authors read and approved the final manuscript. (1) Conception, analysis, and interpretation of data were done by RZ, SK, and NA. (2) Drafting and revising the article were done by $R Z$ and SK. (3) Final approval of the version to be published was done by RZ and NA. (4) RZ and MS agree to be accountable for all aspects of the work if questions arise related to its accuracy or integrity. All authors read and approved the final manuscript.

\section{Funding}

There are no sources of funding to be declared.

\section{Availability of data and materials}

The datasets used and/or analyzed during the current study are available from the corresponding author on reasonable request.

\section{Ethics approval and consent to participate}

The study has been approved by the "Ethical Committee of Faculty of Medicine, Cairo University," in compliance with Helsinki Declaration. A written consent was obtained from the included patients. This study was not issued a reference number by the ethical committee because back then, the approving committee did not apply issuing serial numbers.

\section{Consent for publication}

All the included patients signed an informed consent to publish the data contained within this study.

\section{Competing interests}

The authors declare that they have no competing interests.

\section{Author details}

${ }^{1}$ Department of Diagnostic and Interventional Radiology, Kasr Al-Ainy Faculty of Medicine, Cairo University, 11 rd. 100, Maadi, Cairo, Egypt. ${ }^{2}$ Department of Radiology, National Cancer Institute, Cairo University, Cairo, Egypt.

Received: 28 November 2019 Accepted: 2 December 2019

Published online: 09 January 2020

\section{References}

1. Murphey MD, Ruble CM, Tyszko SM et al (2009) Musculoskeletal fibromatoses: radiologic-pathologic correlation. RadioGraphics 29:21432183. https://doi.org/10.1148/rg.297095138

2. Walker EA, Petscavage JM, Brian PL et al (2012) Imaging features of superficial and deep fibromatoses in the adult population. Sarcoma 2012:117. https://doi.org/10.1155/2012/215810

3. Fletcher CDM, World Health Organization, International Agency for Research on Cancer (2013) WHO classification of tumours of soft tissue and bone, 4th edn. IARC Press, Lyon

4. The ESMO / European Sarcoma Network Working Group (2012) Soft tissue and visceral sarcomas: ESMO Clinical Practice Guidelines for diagnosis, treatment and follow-up. Ann Oncol 23:vii92-vii99. https://doi.org/10.1093/ annonc/mds253

5. Oka K, Yakushiji T, Sato H et al (2011) Usefulness of diffusion-weighted imaging for differentiating between desmoid tumors and malignant soft tissue tumors. J Magn Reson Imaging 33:189-193. https://doi.org/10.1002/ jmri.22406

6. Subhawong TK, Jacobs MA, Fayad LM (2014) Diffusion-weighted MR imaging for characterizing musculoskeletal lesions. Radiographics 34:11631177. https://doi.org/10.1148/rg.345140190

7. Dallaudière B, Lecouvet F, Vande Berg B et al (2015) Diffusion-weighted MR imaging in musculoskeletal diseases: current concepts. Diagn Interv Imaging 96:327-340. https://doi.org/10.1016/j.diii.2014.10.008

8. Weiss SW, G JR, Enzinger FM (2008) Fibromatoses. In: Enzinger and Weiss' soft tissue tumors. Mosby Elsevier, Philadelphia, pp 227-228

9. McCarville MB, Hoffer FA, Adelman CS et al (2007) MRI and biologic behavior of desmoid tumors in children. Am J Roentgenol 189:633-640. https://doi.org/10.2214/AJR.07.2334

10. Dinauer PA, Brixey CJ, Moncur JT et al (2007) Pathologic and MR imaging features of benign fibrous soft-tissue tumors in adults. Radiographics 27: 173-187. https://doi.org/10.1148/rg.271065065

11. Sundaram M, Duffrin H, McGuire MH, Vas W (1988) Synchronous multicentric desmoid tumors (aggressive fibromatosis) of the extremities. Skelet Radiol 17:16-19

12. Rock MG, Pritchard DJ, Reiman HM et al (1984) Extra-abdominal desmoid tumors. J Bone Joint Surg Am 66:1369-1374

13. Vandevenne JE, Schepper AM, Beuckeleer LD et al (1997) New concepts in understanding evolution of desmoid tumors: MR imaging of 30 lesions. Eur Radiol 7:1013-1019

14. Quinn SF, Erickson SJ, Dee PM et al (1991) MR imaging in fibromatosis: results in 26 patients with pathologic correlation. AJR 156:539-542

15. Lee JC, Thomas JM, Phillips S et al (2006) Aggressive fibromatosis: MRI features with pathologic correlation. Am J Roentgenol 186:247-254. https:// doi.org/10.2214/AJR.04.1674

16. McDonald ES, Yi ES, Wenger DE (2008) Extraabdominal desmoid-type fibromatosis. Radiographics 28:901-906. https://doi.org/10.1148/rg. 283075169

17. Shim HS, Kim S-J, Kim OH et al (2014) Fibromatosis associated with silicone breast implant: ultrasonography and MR imaging findings. Breast J 20:645649. https://doi.org/10.1111/tbj.12340

18. Khoo MMY, Tyler PA, Saifuddin A, Padhani AR (2011) Diffusion-weighted imaging (DWI) in musculoskeletal MRI: a critical review. Skelet Radiol 40: 665-681. https://doi.org/10.1007/s00256-011-1106-6

19. Hiwatashi A, Kinoshita T, Moritani T et al (2003) Hypointensity on diffusionweighted MRI of the brain related to T2 shortening and susceptibility effects. Am J Roentgenol 181:1705-1709. https://doi.org/10.2214/ajr.181.6.1811705

20. Einarsdottir H, Karlsson M, Wejde J, Bauer HCF (2004) Diffusion-weighted MRI of soft tissue tumours. Eur Radiol 14:959-963. https://doi.org/10.1007/ s00330-004-2237-0 
21. Pekcevik Y, Onur Kahya M, Kaya A (2015) Characterization of soft tissue tumors by diffusion-weighted imaging. Iran J Radiol:12. https://doi.org/ 10.5812/iranjradiol.15478v2

\section{Publisher's Note}

Springer Nature remains neutral with regard to jurisdictional claims in published maps and institutional affiliations.

Submit your manuscript to a SpringerOpen ${ }^{\circ}$ journal and benefit from:

- Convenient online submission

- Rigorous peer review

- Open access: articles freely available online

- High visibility within the field

- Retaining the copyright to your article

Submit your next manuscript at $\boldsymbol{\triangleright}$ springeropen.com 